\title{
ChemComm
}

\section{Copper/TEMPO catalysed synthesis of nitriles from aldehydes or alcohols using aqueous ammonia and with air as the oxidant $\dagger \neq$}

Cite this: Chem. Commun., 2013, 49, 6030

Received 27th March 2013, Accepted 22nd May 2013

DOI: $10.1039 / c 3 c c 42231 c$

www.rsc.org/chemcomm

Copper/TEMPO catalysts can be used to prepare nitriles from aldehydes or alcohols using aqueous ammonia. Readily accessible methods were developed that enable standard glassware to be used with air as the source of $\mathrm{O}_{2}$. It was further shown that, at higher temperatures in a pressurised reactor under limiting oxygen conditions $\left(8 \% \mathrm{O}_{2}\right)$, catalyst loadings of $1 \mathrm{~mol} \%$ could be employed.

The nitrile group is an important functional group in organic chemistry; used as an intermediate in the synthesis of other functional groups as well as being present in the structure of a number of important fine chemicals and pharmaceuticals. For example, aromatic nitriles are present in a number of leading pharmaceuticals. ${ }^{1}$ Traditional methods for preparing nitriles utilise toxic/dangerous reagents and produce stoichiometric amounts of metal waste. In recent years there have been developments whereby catalysts can be combined with nonmetallic cyano group sources. ${ }^{2}$ These methods offer an improvement, but in most cases still utilise aryl halides as the substrates; which are not always straightforward to prepare. As such, there have been sustained efforts to develop greener catalytic methods. Alcohols and aldehydes are attractive starting materials as these are readily accessed and easy to handle. Although there are a number of reports that utilise aldehydes for the synthesis of nitriles, in many cases the reagents used are not ideal for larger scale applications. For example, they use unstable hydroxylamine ${ }^{3}$ or atom inefficient oxidising agents such as trichloroisocyanuric acid. ${ }^{4}$ Erman et al. prepared nitriles from aldehydes, using simple copper salts (such as $\mathrm{CuCl}$ and $\mathrm{CuCl}_{2}$ ) as the catalyst, $\mathrm{NH}_{3}$ as the nitrogen

\footnotetext{
${ }^{a}$ School of Chemistry and Chemical Engineering, Queen's University Belfast,

David Keir Building, Stranmillis Road, Belfast, BT9 5AG, UK.

E-mail:m.j.muldoon@qub.ac.uk,m.cook@qub.ac.uk

${ }^{b}$ Department of Medicinal Chemistry, AstraZeneca $R \& D$, Charnwood, Bakewell Rd, Loughborough, LE11 5RH, UK

$\dagger$ Dedicated to Professor David J. Cole-Hamilton on the occasion of his retirement and for his outstanding contributions to transition metal catalysis.

† Electronic supplementary information (ESI) available: Further details of experimental procedures and ${ }^{1} \mathrm{H}$ and ${ }^{13} \mathrm{C}$ NMR spectra. See DOI: $10.1039 / \mathrm{c} 3 \mathrm{cc} 42231 \mathrm{c}$ $\S$ Current address: Department of Chemistry, Stanford University, Stanford, CA 94305 , USA.

T Current address: Genentech, Inc., 1 DNA Way, South San Francisco, CA 94080, USA.
}

source and hydrogen peroxide as the oxidant, however the yields reported for a number of substrates were low. ${ }^{5}$ From an atom efficiency point of view the best approach is the catalytic aerobic oxidation of primary imines; formed in situ by the reaction of an aldehyde with ammonia. To date, there are very few reports of aerobic catalytic methods that would be widely applicable to synthetic chemists. Traditionally, this route has been implemented using heterogeneous catalysts under harsh conditions $\left(\right.$ e.g. $\left.300{ }^{\circ} \mathrm{C}\right) .{ }^{6}$ More recently there have been reports of heterogeneous catalysts operating at more reasonable conditions, for example $100-130{ }^{\circ} \mathrm{C} .{ }^{7,8}$ Nonetheless these methods still require the use of pressurised reactors.

There is a need to develop chemoselective oxidation catalysts that can be utilised by the pharmaceutical industry. ${ }^{9}$ To have catalytic oxidation reactions carried out on scale, it would help if these methods were first adopted by synthetic chemists working at the early stages of R\&D. Therefore we believe that it is important that methods are developed that are readily accessible and safe. We wanted to develop a method that did not specifically require specialist high pressure reactors. Additionally, we did not want to employ a pure $\mathrm{O}_{2}$ atmosphere. The use of pure $\mathrm{O}_{2}$ is quite common in the aerobic catalysis literature, but it is a dangerous approach and it is a barrier to such catalysts being widely adopted. We aimed to develop a safe, practical and scalable method. Herein, we report for the first time the use of the Cu-TEMPO-air catalytic system for the oxidation of aldehydes or alcohols to a range of nitriles. ${ }^{10-12} \mathrm{As}$ shown in Scheme 1, this catalyst system consists of a $\mathrm{Cu}$ salt complexed with a ligand such as 2,2-bipyridine (bipy), a stable free
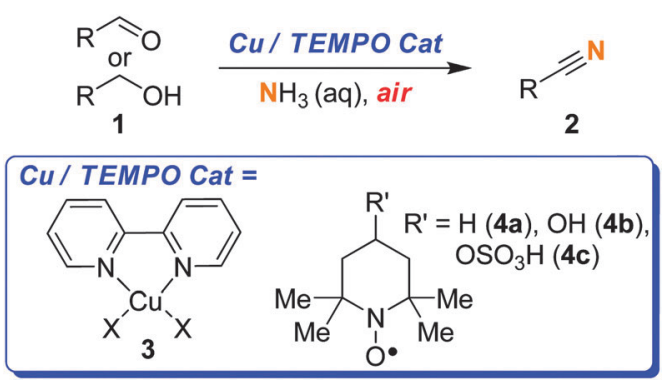

Scheme 1 Synthesis of nitriles using CU/TEMPO. 
Table 1 Optimisation study

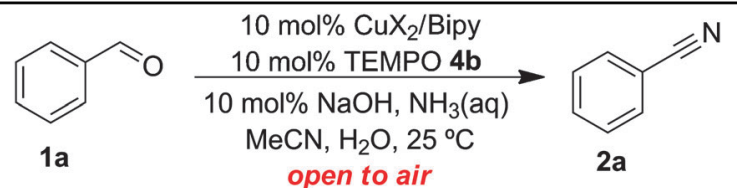

\begin{tabular}{lllcc}
\hline Entry & $\mathrm{CuX}_{2}$ & $\mathrm{NH}_{3}$ addition rate $\left(\mathrm{mL} \mathrm{h}^{-1}\right)$ & Time $(\mathrm{h})$ & Yield (\%) \\
\hline 1 & $\mathrm{CuBr}_{2}$ & 1 & 6 & $0^{a}$ \\
2 & $\mathrm{CuCl}_{2}$ & 1 & 6 & $6^{a}$ \\
3 & $\mathrm{Cu}(\mathrm{OTf})_{2}$ & 1 & 6 & $54^{a}$ \\
4 & $\mathrm{Cu}(\mathrm{OTf})_{2}$ & 0.5 & 6 & $21^{a}$ \\
5 & $\mathrm{Cu}(\mathrm{OTf})_{2}$ & 1.5 & 6 & $32^{a}$ \\
6 & $\mathrm{Cu}(\mathrm{OTf})_{2}$ & 1 & 16 & $95^{b}$ \\
\multicolumn{2}{c}{${ }^{a}$ GC yield. ${ }^{b}$ Isolated yield. } & &
\end{tabular}

radical such as TEMPO (2,2,6,6-tetramethylpiperidinyloxy), and dioxygen (from air) as the terminal oxidant.

The catalyst has been well studied for the aerobic oxidation of alcohols to aldehydes, and we were attracted to this catalyst system as it possesses a number of attributes that make it very desirable. ${ }^{13,14}$ It utilises an inexpensive, abundant metal of low toxicity. It can operate under mild conditions, demonstrates high chemoselectivity and is tolerant of a wide range of functional groups and heteroatoms. The use of this catalyst for the oxidation of alcohols to aldehydes is well established $^{13,14}$ therefore we have mainly focused on examining its new application; the synthesis of nitriles from aldehydes. Some initial optimisation experiments are shown in Table 1. It was found that $\mathrm{Cu}(\mathrm{OTf})_{2}$ was the most active catalyst and was able to afford a high isolated yield of benzonitrile at $25^{\circ} \mathrm{C}$. $\mathrm{Cu}(\mathrm{OTf})_{2}$ was therefore selected as the choice of $\mathrm{Cu}(\mathrm{II})$ species when studying a wider range of substrates (Table 2). The "open flask" approach means that continual addition of $\mathrm{NH}_{3}(\mathrm{aq})$ is required to replace $\mathrm{NH}_{3}$ that evaporates over time. However, if the concentration of $\mathrm{NH}_{3}$ is too high it slows down the rate of the reaction. Reactions were faster when $\mathrm{NaOH}$ was added, however still proceeded readily in its absence.

Once the optimisation had been performed, we examined the substrate scope. As Table 2 demonstrates, good to excellent yields can be obtained for a range of substrates. We have obtained isolated yields for all the products reported in Table 2, although in some cases we have also reported yields determined by GC. In these cases, we attribute the discrepancy in yields to the volatility of the products which led to some loss of the mass balance during product isolation. The reaction is tolerant of a wide range of aromatic functional groups including aryl halides $(\mathbf{1} \mathbf{b}-\mathbf{d})$, nitro groups (1e-f), electron donating groups such as methoxy (19) and enals such as cinnamaldehyde (1h).

The catalyst is also tolerant of molecules containing heteroatoms such as oxygen, sulfur and nitrogen. In the case of the case of $\mathbf{1 j}$ and 11, the nitrile was obtained in good yield, but small quantities of the corresponding primary amide were also obtained. In these cases, if reaction times were prolonged, the nitrile was converted slowly to the amide under the reaction conditions. Mizuno and co-workers reported that primary amides could be produced selectively from oxidation of alcohols or aldehydes in the presence of aqueous ammonia using a heterogeneous Mn catalyst. ${ }^{15}$ For the majority of substrates, the Cu-TEMPO system is selective to nitriles and amide by-products were not observed.
Table 2 Substrate scope

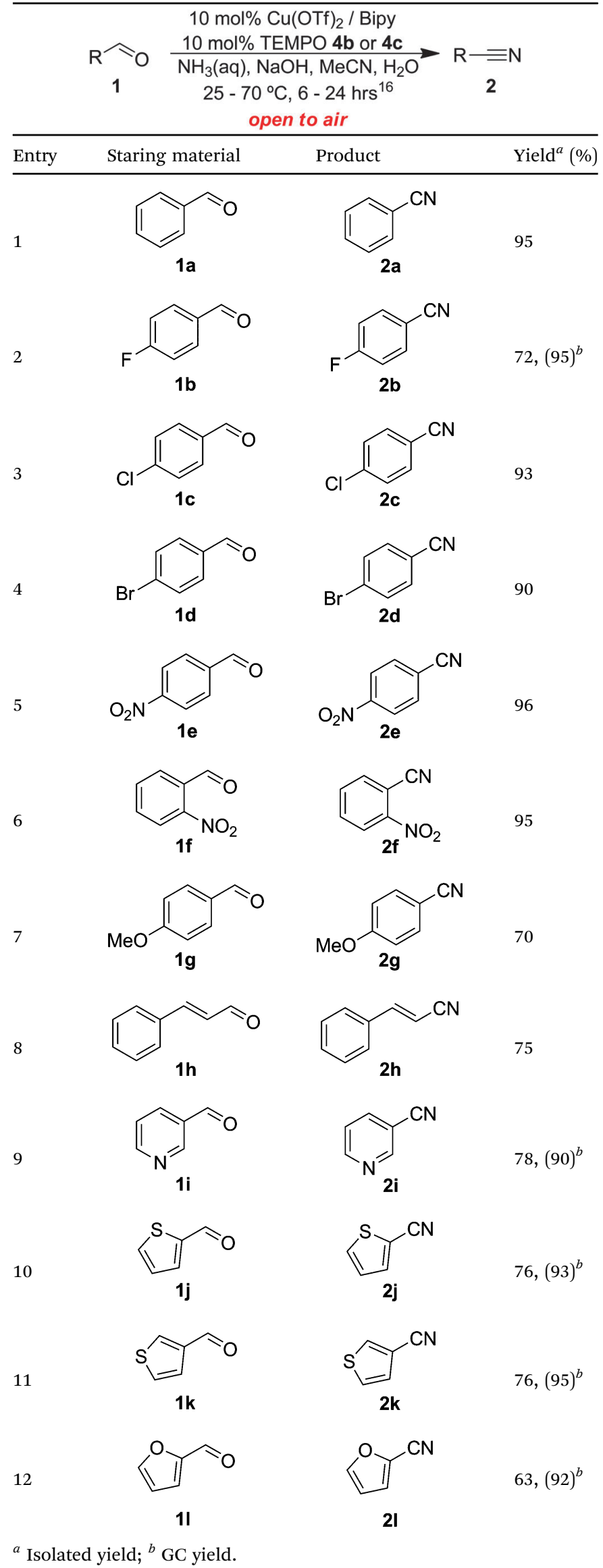


As some of these substrates were slow to react at room temperature, this led us to explore the temperature limits of this open flask approach. Therefore, in some cases, in order to reduce the reaction times we employed temperatures of 40 or $70{ }^{\circ} \mathrm{C} .{ }^{16}$ Above $70{ }^{\circ} \mathrm{C}$ the rate of $\mathrm{NH}_{3}$ evaporation is too great and very little product is obtained. With regards to the choice of radical, although TEMPO (4a) is an effective co-catalyst, we found it difficult to separate from many of the nitrile products using chromatography. In contrast, 4-hydroxy-TEMPO (4b) could be more readily separated from the product. In most cases we utilised 4-sulfonatooxy-TEMPO (4c), ${ }^{16,17}$ as this derivative can be easily separated from the product by aqueous extraction, allowing many of the pure products to be isolated without the need for chromatography. Furthermore, $4 \mathbf{c}$ was found to be more thermally stable than $\mathbf{4 b}$.

As discussed earlier, initial optimisation was carried out at $25{ }^{\circ} \mathrm{C}$, however we later re-examined the use of $\mathrm{CuCl}_{2}$. We found that the use of this less expensive salt becomes viable at higher temperatures. For example, we were able to obtain an $88 \%$ isolated yield of the nitrile from 4-chlorobenzaldehyde with the open air method at $70{ }^{\circ} \mathrm{C}$. If these reactions were scaled up, it would likely be carried out in a pressurised system, utilising limiting oxygen concentrations (LOC), to avoid explosive gas mixtures. The use of reactors has the advantage that higher temperatures can be used as evaporation of ammonia is no longer an issue. Some preliminary tests indicate that at higher temperatures (e.g. $120{ }^{\circ} \mathrm{C}$ ) in a pressurised reactor (with 40 bar of $8 \% \mathrm{O}_{2}$ in $\mathrm{N}_{2}$ ), not only can $\mathrm{CuCl}_{2}$ be utilised but the loading of $\mathrm{CuCl}_{2}$ and $\mathbf{4 c}$ can be reduced to $1 \mathrm{~mol} \%$. Under these conditions we could obtain $83 \%$ isolated yield using 4-chlorobenzaldehyde. Such low catalyst loadings demonstrate the excellent potential for the industrial utilisation of this catalyst system. The results compare favourably to other catalytic methods. For example, the recent work by Mizuno and co-workers, required $10 \mathrm{~mol} \%$ of ruthenium hydroxide on alumina at $120{ }^{\circ} \mathrm{C} .{ }^{7 a}$

In the case of aliphatic aldehydes, we found that we had a problem with undesired, uncatalysed side reactions. It is known that such aldehydes can react with ammonia and produce a range of products via aldol type reactions. ${ }^{18,19}$ We found that such substrates could be converted successfully if we modified our method. Side reactions were reduced by removing $\mathrm{NaOH}$ from the system. As might be expected, aliphatic substrates are less reactive than their aromatic counterparts, therefore we employed $\left[\mathrm{Cu}(\mathrm{MeCN})_{4}\right][\mathrm{OTf}]$ and acetonitrile, rather than an acetonitrilewater mixture. Previously Stahl and co-workers discovered that the reactivity of $\mathrm{Cu} / \mathrm{TEMPO}$ is increased when $\mathrm{Cu}(\mathrm{I})$ salts are employed under such conditions. ${ }^{14 e, g}$ The improved reactivity is not sustained in aqueous solvent mixtures, therefore we could not continually add ammonia as we had previously. Consequently we added just 2.5 equivalents of $\mathrm{NH}_{3}$ (to ensure low levels of water) and instead of an "open flask" we attached a balloon containing air to our condenser. The conditions are summarised in eqn (1). At a temperature of $25{ }^{\circ} \mathrm{C}$ we could obtain octanenitrile (2m) from octanal (1m) in a quantitive yield (determined by GC using nonane as standard). Additionally, starting from the alcohol (1n) we could obtain a quantitive yield of octanenitrile when a temperature of $50{ }^{\circ} \mathrm{C}$ was used. As might be expected, this $\mathrm{Cu}(\mathrm{I})$ approach also allows benzylic nitriles to be prepared directly from their corresponding alcohols.

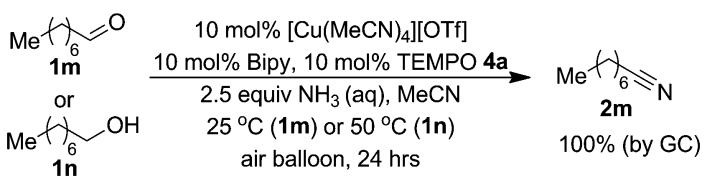

Although not fully optimised, it was once again found that such aliphatic substrates could be converted with lower catalyst loadings when the reactions were carried out in a reactor.

In summary, we have shown that copper/TEMPO can be used to prepare nitriles from aldehydes or alcohols using aqueous ammonia with air as the oxidant. The use of standard glassware along with air means that these methods offer a safe and readily accessible approach to making nitriles using an aerobic catalyst.

We thank the Nuffield Foundation and the Department of Education in Northern Ireland for funding.

\section{Notes and references}

1 Review of nitrile containing pharmaceuticals: F. F. Fleming, L. Yao, P. C. Ravikumar, L. Funk and B. C. Shook, J. Med. Chem., 2010, 53, 7902. 2 A review of nonmetallic cyano-group sources: J. Kim, H. J. Kim and S. Chang, Angew. Chem., Int. Ed., 2012, 51, 11948.

3 E. Wang and G. Lin, Tetrahedron Lett., 1998, 39, 4047.

4 H. Veisi, Synthesis, 2010, 2631.

5 M. Erman, J. Snow and M. Williams, Tetrahedron Lett., 2000, 41, 6749. 6 R. Card and J. L. Schmitt, J. Org. Chem., 1981, 46, 754.

7 (a) T. Oishi, K. Yamaguchi and N. Mizuno, Angew. Chem., Int. Ed., 2009, 121, 6404; (b) T. Oishi, K. Yamaguchi and N. Mizuno, Top. Catal., 2010, 53, 479.

8 T. Ishidaa, H. Watanabe, T. Takei, A. Hamasaki, M. Tokunaga and M. Haruta, Appl. Catal., A, 2012, 425, 85.

9 J. S. Carey, D. Laffan, C. Thomson and M. T. Williams, Org. Biomol. Chem., 2006, 4, 2337.

10 The electrochemically generated nitrosonium ion has been used to oxidize amines to nitriles: M. F. Semmelhack and C. R. Schmid, J. Am. Chem. Soc., 1983, 105, 6732.

$11 \mathrm{Cu} / \mathrm{TEMPO}$ has been used for the oxidation of benzylic amines and anilines to prepare imines and azo compounds. During these studies, it was noted that after prolonged reaction times, nitrile by-products were observed via GC-MS analysis: $\mathrm{Z}$. Hu and F. M. Kerton, Org. Biomol. Chem., 2012, 10, 1618.

12 While this manuscript was under review, two other independent studies were published describing the use of copper/TEMPO catalysis for the oxidative synthesis of nitriles. In both cases these studies utilised pure $\mathrm{O}_{2}$ atmospheres, something that we have avoided: (a) C. Tao, F. Liu, Y. Zhu, W. Liu and Z. Cao, Org. Biomol. Chem., 2013, 11, 3349; (b) W. Yin, C. Wang and Y. Huang, Org. Lett., 2013, 15, 1850.

13 Review: R. A. Sheldon and I. W. C. E. Arends, J. Mol. Catal. A: Chem., 2006, 251, 200.

14 (a) M. F. Semmelhack, C. R. Schmid, D. A. Cortes and C. S. Chou, J. Am. Chem. Soc., 1984, 106, 3374; (b) P. Gamez, I. W. C. E. Arends, J. Reedijk and R. A. Sheldon, Chem. Commun., 2003, 2414; (c) P. Gamez, I. W. C. E. Arends, R. A. Sheldon and J. Reedijk, Adv. Synth. Catal., 2004, 346, 805; (d) E. T. Kumpulainen and A. M. Koskinen, Chem.-Eur. J., 2009, 15, 10901; (e) J. M. Hoover and S. S. Stahl, J. Am. Chem. Soc., 2011, 133, 16901; ( $f)$ J. C. A Flanagan, L. M. Dornan, M. G. McLaughlin, N. G. McCreanor, M. J. Cook and M. J. Muldoon, Green Chem., 2012, 14, 1281; $(g)$ J. M. Hoover, B. L. Ryland and S. S. Stahl, J. Am. Chem. Soc., 2013, 135, 2357.

15 (a) K. Yamaguchi, H. Kobayashi, T. Oishi and N. Mizuno, Angew. Chem., Int. Ed., 2012, 124, 559; (b) K. Yamaguchi, H. Kobayashi, Y. Wang, T. Oishi, Y. Ogasawara and N. Mizuno, Catal. Sci. Technol., $2013,3,318$.

16 See ESI† for more details.

17 V. Strehmel, H. Rexhausen and P. Strauch, Tetrahedron Lett., 2008, 48, 586.

18 H. H. Strain, J. Am. Chem. Soc., 1932, 54, 1221.

19 M. A. Sprung, Chem. Rev., 1940, 26, 297. 